\title{
Cerebrospinal fluid synaptic proteins as useful biomarkers in tyrosine hydroxylase deficiency
}

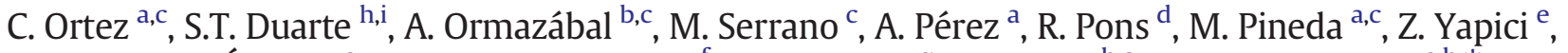 \\ E. Fernández-Álvarez a , R. Domingo-Jiménez ${ }^{f}$, P. De Castro ${ }^{g}$, R. Artuch ${ }^{\text {b,c }}$, A. García-Cazorla ${ }^{\text {a,b,* }}$ \\ a Department of Neurology, CIBER-ER Biomedical Network Research Centre on Rare Diseases, Instituto de Salud Carlos III, Barcelona, Spain \\ ${ }^{\mathrm{b}}$ Department of Biochemistry, CIBER-ER Biomedical Network Research Centre on Rare Diseases, Instituto de Salud Carlos III, Barcelona, Spain \\ c Hospital Sant Joan de Déu (HSJD), CIBER-ER Biomedical Network Research Centre on Rare Diseases, Instituto de Salud Carlos III, Barcelona, Spain \\ d Department of Pediatrics, University of Athens, Aghia Sofia Hospital, Athens, Greece \\ e Istanbul Faculty of Medicine, Department of Child Neurology, Istanbul, Turkey \\ ${ }^{\mathrm{f}}$ Departament of Pediatric Neurology, Hospital V. Arrixaca, Murcia, Spain \\ ${ }^{g}$ Department of Pediatric Neurology, Hospital Gregorio Marañón, Madrid, Spain

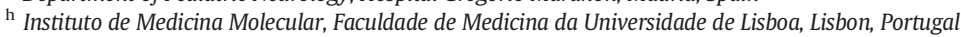 \\ ${ }^{i}$ Hospital Dona Estefânia, CHLC, Lisbon, Portugal
}

\section{A R T I C L E I N F O}

\section{Article history:}

Received 12 August 2014

Received in revised form 27 October 2014

Accepted 28 October 2014

Available online 31 October 2014

\section{Keywords:}

Tyrosine hydroxylase deficiency

Cerebrospinal fluid

Dopaminergic receptor type 2

Infantile parkinsonism

Synaptic proteins

\begin{abstract}
A B S T R A C T
Tyrosine hydroxylase ( $\mathrm{TH}$ ) deficiency is an inborn error of dopamine biosynthesis and a cause of early parkinsonism. Two clinical phenotypes have been described. Type "B": early onset severe encephalopathy; type "A": later onset, less severe and better response to L-dopa. We aimed to study the expression of several key dopaminergic and gabaergic synaptic proteins in the cerebrospinal fluid (CSF) of a series of patients with TH deficiency and their possible relation with the clinical phenotype and response to L-DOPA.

Dopamine transporter (DAT), D2-receptor and vesicular monoamine transporter (VMAT2) were measured in the CSF of 10 subjects with TH deficiency by Western blot analysis. In 3 patients, data of pre- and post-treatment with L-DOPA were available, and in one of them, GABA vesicular transporter was determined. Results were compared to an age-matched control population.

The concentration of D2-receptors in CSF was significantly higher in patients with TH deficiency than in controls. Similarly, DAT and vesicular monoamine transporter type 2 were up-regulated. Studies performed before LDOPA, and on L-DOPA therapy showed a paradoxical response with D2 receptor expression increase as L-Dopa doses and homovanillic concentration gradually raised in a B phenotype patient. The opposite results were found in two patients with A phenotype. However, this is a very small sample, and further studies are needed to conclude robust differences between phenotypes.

Synaptic proteins are detectable in the CSF and their quantification can be useful for understanding the pathophysiology of neurotransmitter defects and potentially to adjust and personalize treatments in the future.
\end{abstract}

(C) 2014 Elsevier Inc. All rights reserved.

\section{Introduction}

Tyrosine hydroxylase (TH) deficiency (OMIM 191290) is a rare autosomal recessive inborn error of dopamine transmission. TH converts tyrosine into L-DOPA, the direct precursor of catecholamine biosynthesis (Fig. 1). This enzymatic conversion is a rate-limiting step in the biosynthesis of catecholamines. Around sixty patients with TH deficiency have been reported worldwide [1-11]. TH deficiency causes a neurological disease with predominant extrapyramidal signs and a variable response to L-DOPA. Although different neurological manifestations have been described (recessive form of Segawa disease, infantile

\footnotetext{
* Corresponding author at: Neurology Department, Hospital Sant Joan de Deu, Passeig Sant Joan de Deu, 2, 08950 Esplugues, Barcelona, Spain. Fax: + 34932033959.

E-mail address: agarcia@hsjdbcn.org (A. García-Cazorla).
}

parkinsonism with dystonia, early-onset progressive encephalopathy), a comprehensive review[7] has divided them into two main forms: type $\mathrm{A}$, a progressive hypokinetic-rigid syndrome plus dystonia, with onset in infancy or childhood; and type B, a complex encephalopathy with neonatal or early infancy onset (hypokinetic-rigid syndrome plus developmental delay, a variety of movement disorders and occasionally epilepsy). Generally, motor and cognitive prognosis is worse in type B. However, the pathophysiological aspects that may underlie these differences have been poorly described. Although TH deficiency is a disease of neuronal communication, the role of key synaptic proteins responsible for dopaminergic transmission has not been reported so far. Synaptic transmission depends on neurotransmitter pools stored within vesicles that undergo regulated exocytosis. In the case of dopaminergic transmission, the vesicular monoamine transporter-2 (VMAT2) is responsible for the loading of dopamine (DA) and other monoamines into synaptic 


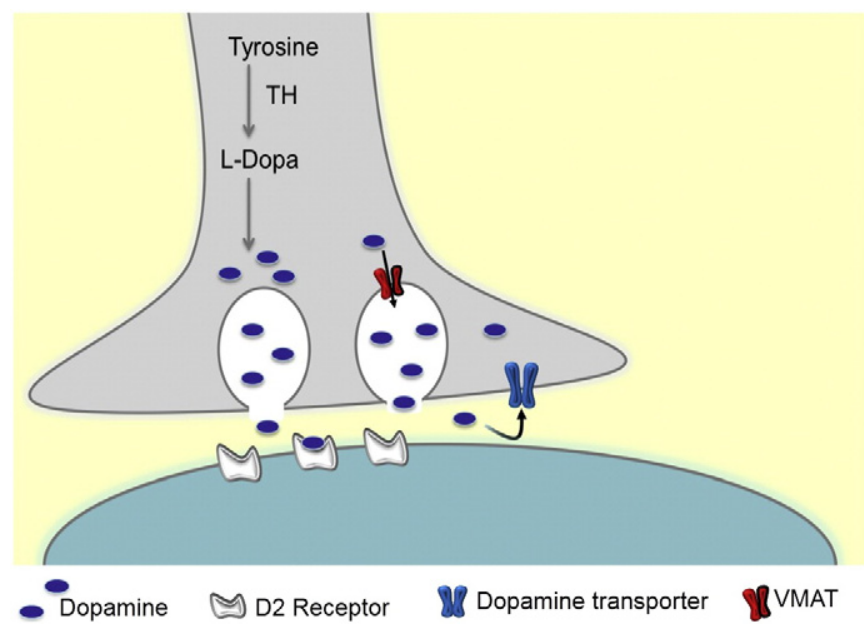

Fig. 1. Schematic representation of dopaminergic synapse and synaptic proteins studied. VMAT2 (vesicular monoamine transporter 2).

vesicles [12]. The DA transporter (DAT) carries DA across the plasmalemmal membrane from the synaptic cleft into the cytoplasm [13]. The central actions of DA are mediated by five distinct receptors that belong to the G-protein receptor family (Fig. 1). They are classified as D1-like (D1 and D5) and D2-like (D2, D3 and D4), and their interaction with dopamine translates into activation/inhibition of specific neurons and circuitries [14]. D2-receptor (D2 R) genetic mutations are related to postural abnormalities, bradykinesia, impaired coordination and prolonged periods of immobility [15]. These symptoms are also characteristic of patients suffering from other dopaminergic neurotransmission disorders. Following recent reports on the co-release of classical neurotransmitters and on interactions between different neurotransmission pathways, we wanted to explore the role of the GABA vesicular transporter (GABAVT), which gives an estimation of GABA release, after L-DOPA treatment.

The detection and quantification of dopaminergic and GABAergic synaptic proteins in the CSF of a control population have been previously reported by our group [16]. We aimed to study synaptic proteins involved in dopaminergic and GABAergic transmission in the CSF of patients with TH deficiency, in order to relate their expression to the different clinical phenotypes and L-DOPA response.

\section{Methods}

\subsection{Patients}

Ten patients with diverse pathogenic mutations in tyrosine hydroxylase gene were diagnosed at Hospital Sant Joan de Déu, Barcelona, from 2002 to 2010. Some of them have been already published as individual case reports $[5,6,8,17]$. Clinical, biochemical and molecular data of the whole series are described in Table 1 . Five patients were classified as "B" phenotype and five as "A". Follow-up and detailed response to L-dopa treatment are also reported in Table 1.

\subsection{CSF studies}

CSF samples from patients were collected by lumbar puncture as previously described $[18,19]$. After lumbar puncture, the first ten drops were used for routine cytochemical/microbiological studies and then CSF was immediately stored in 4 aliquots at $-80{ }^{\circ} \mathrm{C}$ until the moment of analysis. Biogenic amines metabolites and synaptic proteins were analyzed in the next 20 drops.
Biogenic amines metabolites were analyzed by high performance liquid chromatography (HPLC) with electrochemical and fluorescence detection, respectively. Results were compared to our reference values that were established in a control population from our geographical area. Details of reference interval establishment were reported elsewhere [19].

The synaptic proteins, VMAT2, DAT and D2R, involved in dopaminergic transmission, were analyzed by Western blot. In 3 patients $(5,6,7$ in Table 1), these proteins were studied before and after L-dopa treatment, and included GABA vesicular transporter (GABA VT), which gives an estimation of GABA release, in patient 5. Furthermore, GFAP (glial fibrillar acidic protein) was also analyzed as loading and protein concentration inner control of the technique. A total of $40 \mu \mathrm{l}$ of CSF sample was loaded into the gel and proteins were separated on $10 \%$ sodium dodecyl sulfatepolyacrylamide gels (SDS-PAGE) and transferred to polyvinylidene difluoride (PVDF) membranes (Amersham ${ }^{\mathrm{TM}}$ Hybond $^{\mathrm{TM}}$-ECL, GE Healthcare). Membranes were blocked in TBST buffer (0.02 M Tris-base, pH7.6, $0.8 \% \mathrm{NaCl}, 0.1 \%$ Tween 20 ) with $5 \%$ dried skimmed milk for 60 min. Anti-DAT extracellular loop (1:1000; Sigma $\left.{ }^{\circledR}\right)$, anti-D2 R (1:1000; Millipore $\left.{ }^{\circledR}\right)$, anti-VMAT 2 (1:1000; Santa Cruz Biotechnology $\left.{ }^{\circledR}\right)$, anti-GABA VT (1/500; Millipore $\left.{ }^{\circledR}\right)$ and anti-GFAP (1:1000; Santa Cruz Biotechnology $\left.{ }^{\circledR}\right)$ antibodies were added, and incubated at $4{ }^{\circ} \mathrm{C}$ overnight. Membranes were washed three times with TBST buffer and then incubated with appropriate anti-rabbit (1:3000, Promega $\left.{ }^{\circledR}\right)$ or anti-mouse $\left(1: 5000\right.$, Promega $\left.{ }^{\circledR}\right) \operatorname{IgG}$ secondary antibodies at room temperature for $1 \mathrm{~h}$. The blot was then washed six times with TBST and signal was revealed with ECL (Pierce ${ }^{\circledR}$ ECL Western Blotting Substract, Thermo Scientific). Relative levels of each protein were quantified by measuring optical densities (OD) of the corresponding bands with Quantity One ${ }^{\circledR}$ V 4.3.1. software. CSF total protein was measured by standard automated procedures in an Architect ci8200 analyzer (Abbott, USA). Results of synaptic proteins were compared to a control population whose CSF samples were submitted to our laboratory for analysis under suspicion of nervous system infection.. Exclusion criteria were diagnosis of viral or bacterial meningitis, a chronic neurological condition, and hematic or xanthochromic CSF (blood contamination). We studied 3 to 5 agematched controls for every patient with the exception of the oldest patients, aged 17 and 30 years. Since HSJD is a pediatric hospital, we could only recruit two and one controls respectively.

Samples from patients were obtained in accordance with the Helsinki Declaration of 1964 , as revised in 2000 . Written informed consent was obtained from legal guardians of all patients included. The ethical committee of the Hospital Sant Joan de Déu approved the study.

\subsection{Statistical analysis}

All analyses were performed by using SPSS 20.0. Student's $t$-test was used to find differences in synaptic proteins between patients and controls. A $P$ value $<0.05$ was considered significant.

\section{Results}

3.1. Differences in synaptic proteins between patients (before treatment) and controls

Total protein concentration in the CSF samples from patients and controls was within normal limits according to different age ranges (data not shown). DAT, D2R, VMAT2 and GABA vesicular transporter were clearly detectable at the expected molecular weight using conventional western blot analysis in all the CSF samples studied (Fig. 2). The concentration of dopaminergic proteins D2R, DAT and VMAT2 in CSF measured by the average optical density (AOD) was significantly higher in pre-treated patients than in controls $(p<0.0001)$ (Fig. 3A). 
Table 1

Clinical, biochemical and molecular data of the patients included.

\begin{tabular}{|c|c|c|c|c|c|c|c|c|c|c|}
\hline Patient & 1 & 2 & 3 & 4 & 5 & 6 & 7 & 8 & 9 & 10 \\
\hline Origin & Greek & & & & Spanish & & & & Turkish & \\
\hline Onset age/sex & $3 \mathrm{~m} / \mathrm{F}$ & $3 \mathrm{~m} / \mathrm{F}$ & $1 \mathrm{~m} / \mathrm{F}$ & $3 \mathrm{~m} / \mathrm{F}$ & $5 \mathrm{~m} / \mathrm{F}$ & $3 \mathrm{~m} / \mathrm{F}$ & $6 \mathrm{~m} / \mathrm{F}$ & $4 \mathrm{~m} / \mathrm{F}$ & $3 \mathrm{y} / \mathrm{M}$ & $2.5 \mathrm{y} / \mathrm{M}$ \\
\hline Age at diagnosis/treatment & $2 \mathrm{y} / 2 \mathrm{y}$ & $5 \mathrm{~m} / 5 \mathrm{~m}$ & $5 \mathrm{~m} / 5 \mathrm{~m}$ & $8 \mathrm{y} / 8 \mathrm{y}$ & $3 y / 3 y$ & $2.5 \mathrm{y} / 2.5 \mathrm{y}$ & $19 \mathrm{~m} / 19 \mathrm{~m}$ & $11 \mathrm{~m} / 11 \mathrm{~m}$ & $17 \mathrm{y} / 3 \mathrm{y}$ & $30 \mathrm{y} / 2.5 \mathrm{y}$ \\
\hline Oculogyric crisis & ++ & + & ++ & + & ++ & ++ & + & - & - & \\
\hline Dystonia & Generalized & $\begin{array}{l}\text { Intermitent } \\
\text { segmental }\end{array}$ & Intermitent & Generalized & - & $\begin{array}{l}\text { Upper } \\
\text { limbs }\end{array}$ & Pes Equino Varo & - & $\begin{array}{l}\text { Generalized (truncal and } \\
\text { cervical prominent) }\end{array}$ & Generalized \\
\hline Tremor & ++ & + & + & + & + & + & ++ & ++ & - & + \\
\hline Hypokinesia & ++ & ++ & ++ & ++ & ++ & ++ & ++ & ++ & + & ++ \\
\hline Rigidity & - & - & - & - & ++ & ++ & + & + & + & ++ \\
\hline Autonomic dysfunction & + & + & + & + & + & + & - & - & - & - \\
\hline Response to L-dopa & $\begin{array}{l}\text { Gradual improvement. } \\
\text { Slow titration due to } \\
\text { dyskinesias }\end{array}$ & $\begin{array}{l}\text { Initially } \\
\text { good } \\
\text { response } \\
\left({ }^{*}\right)\end{array}$ & $\begin{array}{l}\text { Gradual improvement. } \\
\text { Slow titration due to } \\
\text { dyskinesias.At present } \\
\text { "almost normal" }\end{array}$ & $\begin{array}{l}\text { Very slow } \\
\text { improvement. Slow } \\
\text { titration due to } \\
\text { dyskinesias }\end{array}$ & $\begin{array}{l}\text { Slow } \\
\text { improvement. } \\
\text { Autonomous } \\
\text { gait. Initially } \\
\text { dyskinesias } \\
\text { after slow L- } \\
\text { dopa } \\
\text { increases }\end{array}$ & $\mathrm{N}$ & $\mathrm{N}$ & $\mathrm{N}$ & $\mathrm{N}$ & $\mathrm{N}$ \\
\hline Cognitive function & $\begin{array}{l}\text { Difficult to asses due to } \\
\text { severe dysarthria, but } \\
\text { relatively preserved }\end{array}$ & $\begin{array}{l}\text { Difficult to } \\
\text { asses due to } \\
\text { severe } \\
\text { dysarthria, } \\
\text { but } \\
\text { relatively } \\
\text { preserved }\end{array}$ & $\begin{array}{l}\text { Difficult to asses due to } \\
\text { dysarthria, but } \\
\text { relatively preserved }\end{array}$ & $\begin{array}{l}\text { Difficult to assess due to } \\
\text { severe motor } \\
\text { impairment }\end{array}$ & $\begin{array}{l}\text { Severe mental } \\
\text { retardation } \\
\text { No language }\end{array}$ & $\begin{array}{l}\text { Normal IQ } \\
\text { (tested at } \\
6 \text { years) }\end{array}$ & $\begin{array}{l}\text { Normal IQ (tested at } \\
4 \text { years) }\end{array}$ & $\begin{array}{l}\text { Normal IQ } \\
\text { (tested at } \\
4.5 \text { years) }\end{array}$ & $\begin{array}{l}\text { Normal IQ (tested } \\
\text { at } 6 \text { years) }\end{array}$ & $\begin{array}{l}\text { Normal IQ } \\
\text { (tested at } \\
19 \text { years) }\end{array}$ \\
\hline Phenotype & B & B & B & B & B & A & A & A & A & A \\
\hline HVA (range nmol/l) & $\begin{array}{l}50 \\
(344-906)\end{array}$ & $\begin{array}{l}31 \\
(354-1328)\end{array}$ & $\begin{array}{l}18.5 \\
(354-1328)\end{array}$ & $\begin{array}{l}5 \\
(158-596)\end{array}$ & $\begin{array}{l}15 \\
(304-658)\end{array}$ & $\begin{array}{l}74 \\
(344-906)\end{array}$ & $\begin{array}{l}151 \\
(304-658)\end{array}$ & $\begin{array}{l}158 \\
(344-906)\end{array}$ & $\begin{array}{l}53 \\
(156-410)\end{array}$ & $\begin{array}{l}23 \\
(156-410)\end{array}$ \\
\hline HVA/HIAA & $\begin{array}{l}0.25 \\
(1.5-3.5)\end{array}$ & $\begin{array}{l}0.11 \\
(1.5-3.5)\end{array}$ & $\begin{array}{l}0.08 \\
(1.5-3.5)\end{array}$ & $\begin{array}{l}0.03 \\
(1.5-3.5)\end{array}$ & $\begin{array}{l}0.05 \\
(1.5-3.5)\end{array}$ & $\begin{array}{l}0.42 \\
(1.5-3.5)\end{array}$ & $\begin{array}{l}1.06 \\
(1.5-3.5)\end{array}$ & $\begin{array}{l}0.64 \\
(1.5-3.5)\end{array}$ & $\begin{array}{l}0.73 \\
(1.5-3.5)\end{array}$ & $\begin{array}{l}0.58 \\
(1.5-3.5)\end{array}$ \\
\hline $\begin{array}{l}\text { CSF protein concentration } \\
(\mathrm{mg} / \mathrm{dl}) *\end{array}$ & 21 & 19 & 17 & 30 & 15 & 15 & 32 & 19 & 22 & 25 \\
\hline Mutations in the TH gene & p.L236P/p.L236P & & & & $\begin{array}{l}\text { p.R328W } \\
\text { p.T399M }\end{array}$ & $\begin{array}{l}\text { c.1-71C }>\mathrm{T} \\
\text { c.1-71C }>\mathrm{T}\end{array}$ & $\begin{array}{l}\text { c.1-70G }>\mathrm{A} / \\
\text { c. }\left[1197+25 \_1391 \mathrm{del}\right]\end{array}$ & p.R233H/p.R233H & & \\
\hline
\end{tabular}

+ : slight to moderate. ++: severe. -: absent. F: female. M: male. M: months. MR: mental retardation. NI: no information. N: normalization of symptoms. Y: years.

Values of D2R, DAT and VMAT correspond to optical densities. * Normal range: $15-40 \mathrm{mg} / \mathrm{dl}$.

Patient $\mathrm{N}^{\circ} 2\left(^{*}\right)$ : Initially good response with no dyskinesias, but she stopped treatment for one year and when she returned and was started back on L-dopa then she showed dyskinesias. 
3.2. Synaptic proteins in patients before treatment according to different clinical, biochemical and genetic characteristics

\subsubsection{With regard to clinical phenotypes}

the overall expression of synaptic proteins was higher in phenotype A than in B. However, this difference was mainly due to the very high expression of D2, DAT and VMAT2 in patients 9 and 10, in whom CSF was obtained $24 \mathrm{~h}$ after the withdrawal of L-DOPA. These patients had received long-term treatment with L-DOPA (14 and 27 years, respectively) and stopped only to quantify neurotransmitters for diagnostic purposes. The remaining patients underwent their CSF study not only much earlier in time, but without any previous L-DOPA exposure.

When considering all patients, we observed that $\mathrm{D} 2$ receptors had a higher expression in the A (AOD: $153 \times 10^{4}$; SEM: $346 \times 10^{3}$ ) than in B (AOD: $115 \times 10^{4}$; SEM: $399 \times 10^{3}$; Student's $t$ test was not done due to the small size of every group). However, excluding patients 9 and 10, B phenotype had a greater D2R expression than A (in A, AOD: $103 \times 10^{4}$; SEM: $106 \times 10^{3}$; in "B": AOD: $115 \times 10^{4}$; SEM: $\left.399.6 \times 10^{4}\right)$. When individual cases were analyzed, we observed (Fig. 3B) that patients with the B phenotype presented a broad variability of D2R expression, with the highest values in patients 2 and 5 . Patient 5 had the most severe clinical phenotype of our series (Table 1 ), with generalized dyskinesias and severe mental retardation. Patient 2 showed an initial good response and tolerance to L-DOPA, but treatment was discontinued for one year and she showed generalized dyskinesias when L-dopa was reintroduced. However, the remaining B phenotype patients had also L-dopa induced dyskinesias without a similar high level of D2R expression. Interestingly, patient 3, who showed the most favorable outcome amongst the B phenotype patients, had the lowest D2R expression.

Global DAT expression was also higher in A phenotype than in B (in "A", AOD: $137 \times 10^{4}$, SEM: $346 \times 10^{3}$, whereas in "B": AOD: $953 \times 10^{3}$ SEM: $\left.399 \times 10^{3}\right)$. The same pattern was also observed with VMAT2 expression (in "A", AOD: $180 \times 10^{4}$, SEM: $355 \times 10^{3}$, and in "B", AOD: $106 \times 10^{4}$, SEM: $434 \times 10^{3}$ ).

\subsubsection{With regard to HVA concentration and HVA/HIAA ratio}

patients with the $B$ phenotype had in general lower concentration (from 5 to $50 \mathrm{nmol} / \mathrm{l}$; mean: 23.9) than phenotype A patients (from 23 to $158 \mathrm{nmol} / \mathrm{l}$; mean: 91.8). HVA concentrations in our oldest patients (9 and 10) were lower than expected for A phenotypes, but as already mentioned, these patients are an exception in terms of age and longterm L-DOPA therapy. HVA/HIAA ratio followed a similar behavior, being much lower in $B$ phenotype patients (range 0.03-0.25; mean: 0.10 ), compared to A phenotype patients (range 0.42-1.06; mean: 0.77).

Finally, we did not observe any association between genotype and the expression of the synaptic proteins studied.

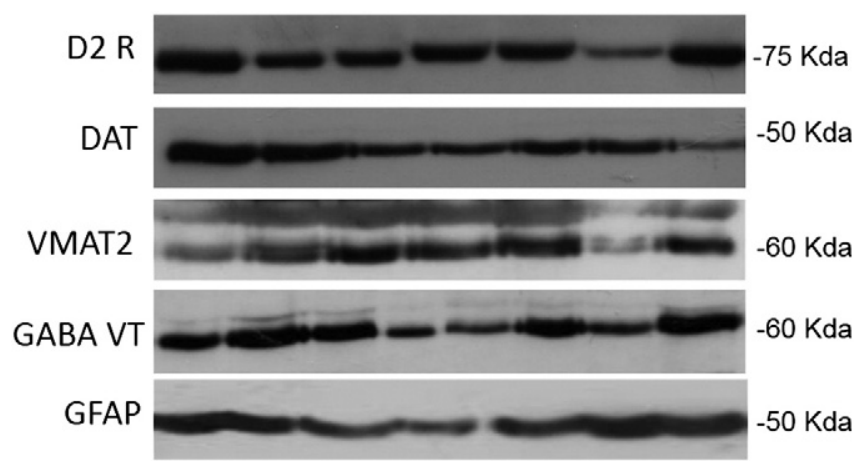

Fig. 2. Immunoblot analysis of the proteins included in the study. VMAT2 (vesicular monoamine transporter 2), D2 (D2 receptor), DAT (dopamine transporter), GABAVT (GABA vesicular transporter), and GFAP (glial fibrillar acidic protein).

\subsection{Synaptic proteins before and after L-dopa treatment}

In those patients with CSF study before L-dopa treatment and on L-dopa treatment we observed that the expression of synaptic proteins, and notably D2R, was different depending on the phenotypes. Patients with the A phenotype (6 and 7) had a decrease in the expression of D2R after treatment that corresponds to a simultaneous increase in their HVA concentrations (Fig. 4). Patient 5 (B phenotype) had several CSF studies performed at progressively higher L-dopa doses, that showed an unexpected higher expression of D2R in spite of a global tendency of increase and normalization in HVA concentrations (Fig. 4A). Moreover GABAVT, an estimator of GABA release had also a progressive increase in parallel to L-dopa doses and HVA concentration (Fig. 4,B and C).

\section{Discussion}

In this study we aimed to describe the expression of some key synaptic dopaminergic and gabaergic proteins in the CSF of ten patients with TH deficiency, the relationship with the clinical phenotype and with the response to L-DOPA. Our series has a relatively significant size, since fewer than sixty patients have been reported worldwide $[1-11,17]$. To our knowledge, this is the first study to measure the concentration of synaptic proteins involved in neurotransmission in the CSF of patients with TH deficiency.

One of the most intriguing features in this disease is the pathophysiology of the two main different phenotypes, and in particular, the variable response and tolerance to L-dopa, a factor related to the global outcome. Patients with the severe phenotype have an early onset complex encephalopathy or infantile parkinsonism with pyramidal tract dysfunction, developmental delay, oculogyric crisis and poor or moderate treatment response. However, some of our patients with favorable outcome and classified as A or mild phenotype (patients 6, 7 and 8), had also a very early start of symptoms (below 6 months of age) and a clinical picture of complex infantile parkinsonism as severe as our B patients. Although early introduction of treatment is related to a most favorable outcome [7], some of our A patients with very severe early symptoms did not start treatment until 2.5 years of age (patient 6 ) and managed nonetheless to achieve a normal psychomotor development. These considerations suggest that although phenotype classifications are necessary and useful, in some cases it is difficult to set up clear limits and overlaps between predetermined characteristics easily appear.

In the population studied, the levels of HVA and the HVA/HIAA ratio in CSF, as well as a positive, rapid and early response to treatment with L-DOPA, were the main determinants of a favorable outcome, rather than age at onset or initial clinical features.

It has been already described that the phenotypes and treatment outcomes are related to the lowest HVA levels and a HVA/5-HIAA ratio of less than 1 in the $\operatorname{CSF}[7,9,10]$. Clinical features compatible with dopa-responsive dystonia were the most salient features of the two other patients with A phenotype (9 and 10). In spite of the good outcome, both of them had rather low HVA CSF values. However, we have not found previous data in the literature on HVA concentrations in juvenile and adult ages (17 and 30 years) and on patients who have received long-term treatment with L-DOPA.

In addition, it is not known what the role of the time period of discontinuation of L-dopa before the collection of CSF for analysis is.

With regard to the study of synaptic proteins, all were easily detectable at the expected molecular weight by the same procedures as previously reported [16]. We observed a baseline significant higher expression of D2R, DAT and VMAT in our patients compared to our age-matched control population. This is compatible with an upregulation of post-synaptic D2 receptor and a high functioning of dopamine reuptake (DAT) as a consequence of a chronic low dopamine exposition at the synaptic cleft.

Although we expected to find the highest D2R expression in all those patients with very low values of HVA, this finding was not constant. 
a

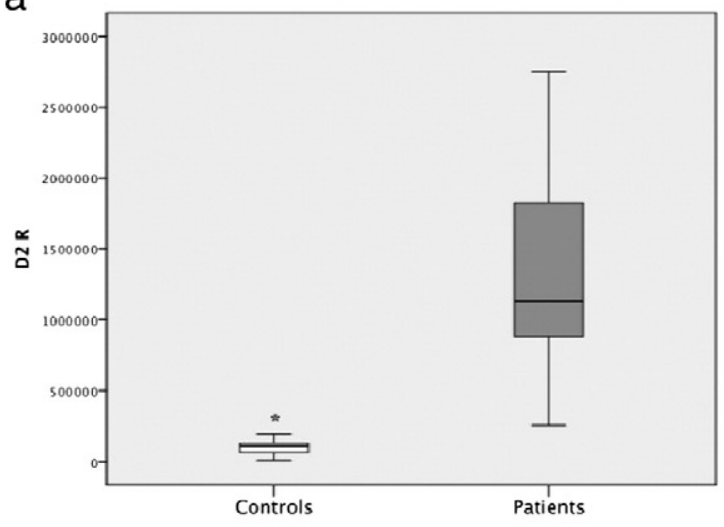

\begin{tabular}{|l|l|l|l|l|l}
\hline \multicolumn{2}{|c|}{} & $\begin{array}{l}\text { Average } \\
\text { Optic } \\
\text { Density }\end{array}$ & $\begin{array}{l}\text { Standart } \\
\text { Error } \\
\text { Mean }\end{array}$ & $\begin{array}{l}\text { Confidence } \\
\text { Interval }\end{array}$ & P value \\
\hline \multirow{3}{*}{ D2 R } & Controls & 100934.78 & 8186.82 & 95 & .00 \\
\cline { 2 - 5 } & Patients & 1343806.7 & 257136.91 & & \\
\hline DAT & Controls & 92522.08 & 11784.32 & 95 & .00 \\
\cline { 2 - 4 } & Patients & 1163322.1 & 194851.23 & & \\
\hline \multirow{3}{*}{ VMAT } & Controls & 197534.23 & 22040.66 & 95 & .00 \\
\cline { 2 - 4 } & Patients & 1428417.20 & 292096.79 & & \\
\hline
\end{tabular}

b
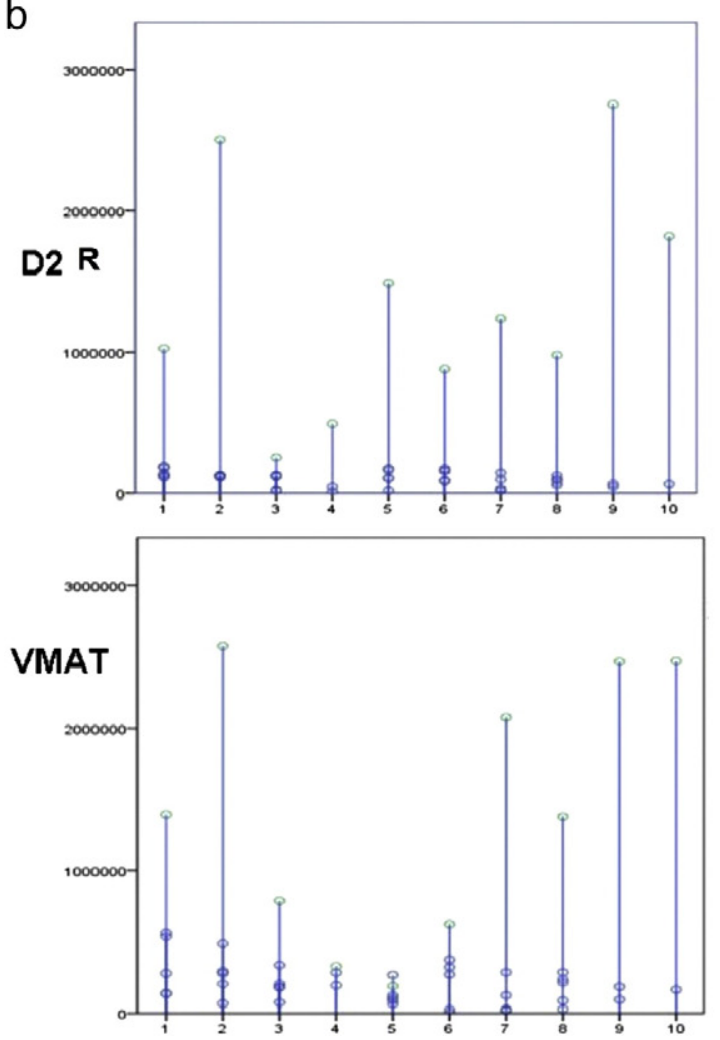
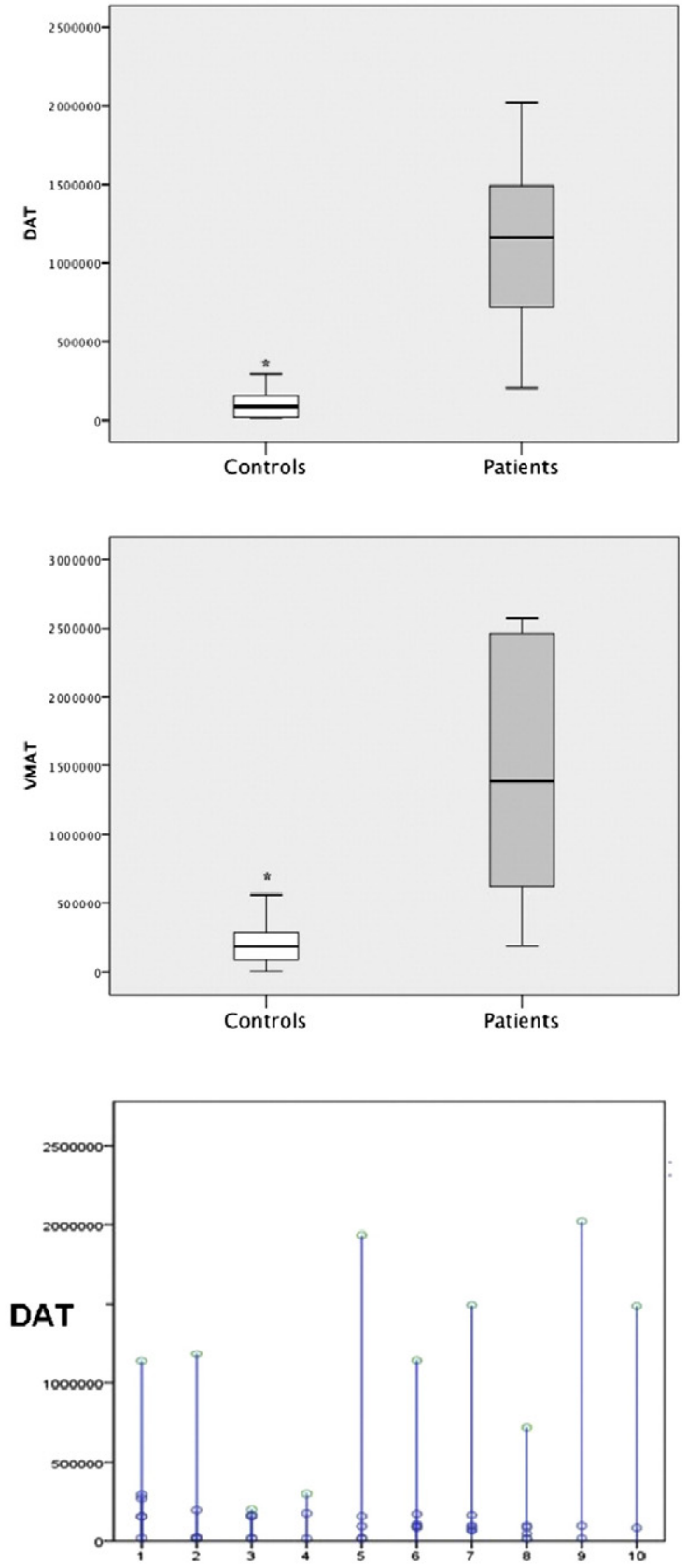

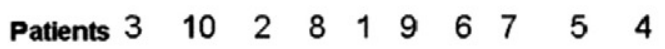

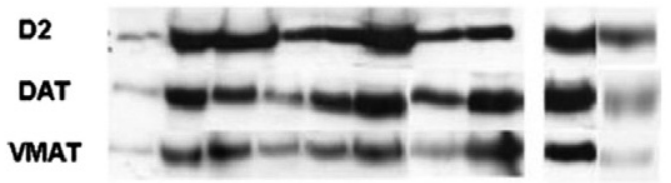

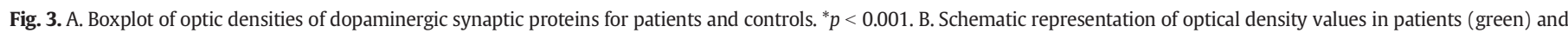
controls (blue). 
A

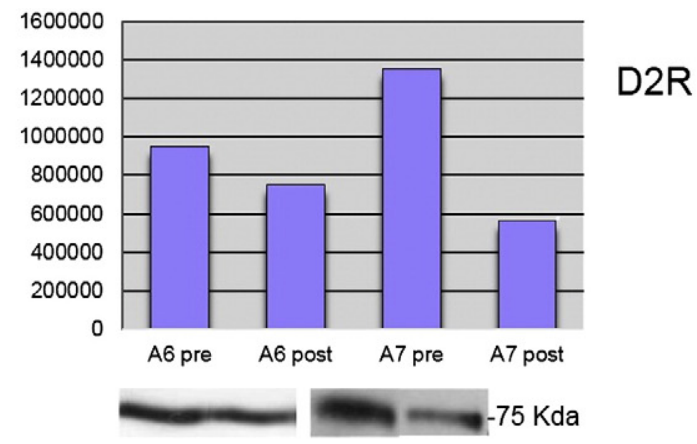

B

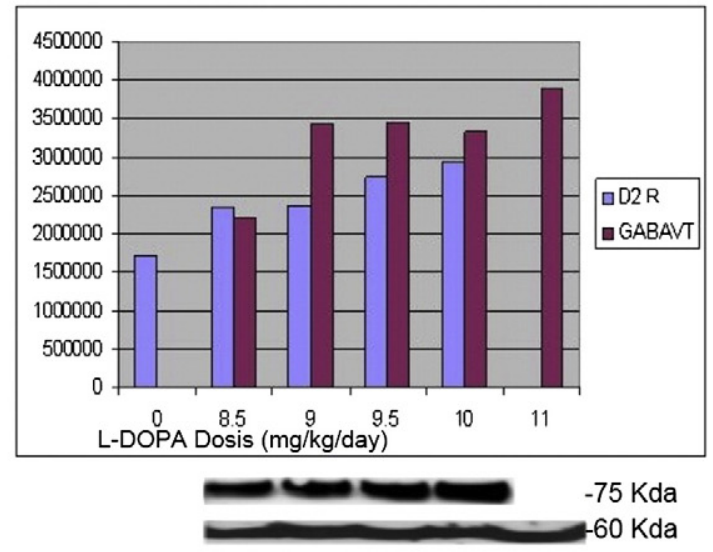

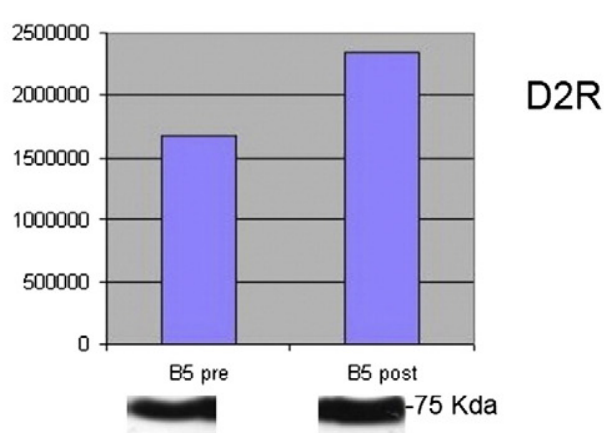

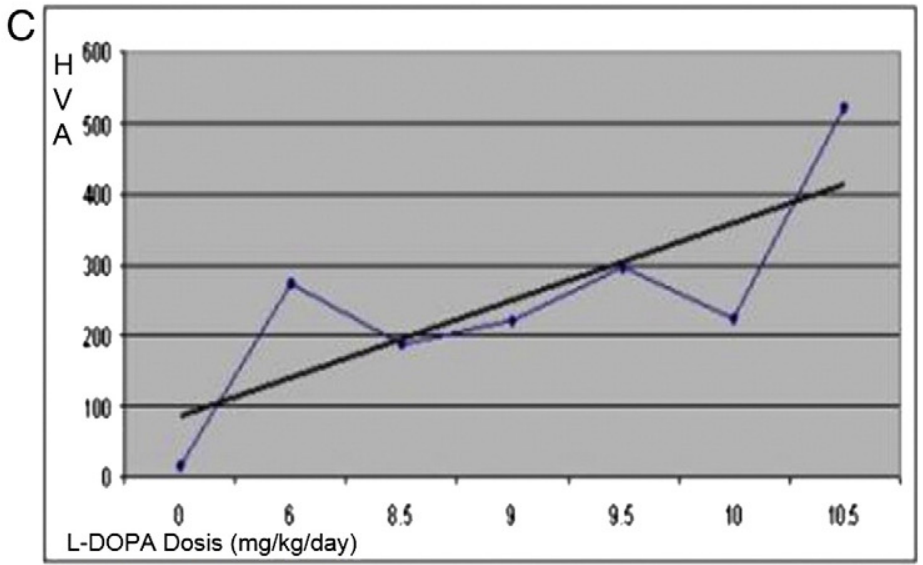

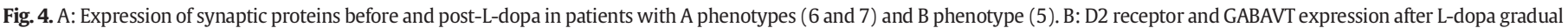

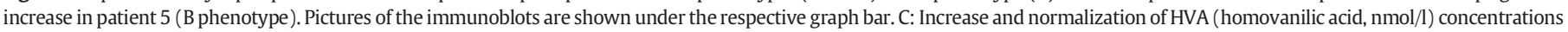
in consonance with $\mathrm{L}$-dopa gradual increase in patient 5 .

Most of them, patients 2, 5, 9 and 10 predictably presented very high D2R expression together with very low HVA values. However, patients 3 and 4 , also with extremely low HVA levels, showed the lowest D2R expression.

Interestingly, we found relevant differences in the expression of D2R when comparing the CSF before and after L-DOPA treatment. Two patients with A phenotype ( 6 and 7 ) achieved an adequate D2R response by decreasing its expression (downregulation) as L-DOPA doses and HVA concentration raised. On the other hand, our only B patient (5) with several CSF samples, at gradually higher L-DOPA doses presented a paradoxical response by progressively increasing its expression (permanent upregulation) even in the presence of normal HVA values. It has been widely demonstrated in basic research studies that dopamine plays a vital role in brain development from the first prenatal stages $[7,20]$. Dopamine is also a neurotrophic factor involved in synapse formation and brain wiring during development [21]. Chronic early dopamine deficiency might cause very diverse functional and microstructural abnormalities that result in mental retardation and various neurological disabilities. The abnormal behavior of D2R in our patient could be a consequence of this persistent severe dopamine deficiency. Unfortunately, we do not have other post-L-DOPA CSF samples from patients with a similar outcome. Our study shows different D2R expression regarding L-DOPA response in both phenotypes, in a very small sample of patients. These results remain preliminary and need further collaborative studies in order to conclude robust differences between phenotypes.

Studies about dopaminergic receptors in Parkinson's Disease (PD), an adquired status of dopaminergic denervation, have shown structural changes in the striatal microcircuit, including an abnormal functional interaction between D1 and D2 receptors in the control of motor function[22]. Because PD is primarily characterized by the degeneration of dopaminergic neurons projecting into the striatum, several studies have been performed to characterize the modification of the main forms of striatal neuronal plasticity in experimental models of $\mathrm{PD}[23]$.
These morphological changes are permanent and as a consequence, the basal ganglia enters an 'abnormal state' that eventually precludes the opportunity for the restoration of normal motor function through dopamine replacement therapy at later time points[22]. In particular, dopamine depletion, in addition to direct performance effects, will result in inhibitory learning in the indirect pathway that will impair future performance and learning even when dopamine signaling is restored [24]. Several studies suggest that loss of dopamine signaling at D2 receptors can invert corticostriatal plasticity in the striatopalidal pathway, which could underlie aberrant learning. Diminished dopamine will favor the indirect "inhibitory" striatopallidal NOGO pathway because of greater activity in D2-expressing MSNs as a consequence of less activation of D2 R [24]. Therefore, the abnormal motor patterns observed in status of dopamine depletion like PD and TH deficiency disease probably reflect the induction of abnormal neural circuitries within the basal ganglia network, that can be more or less reversible with L-DOPA treatment in each patient.

In summary, the analysis of synaptic proteins' expression provides an original approach for the study of inborn errors of neurotransmitters. In particular, these studies may introduce novel insights into the pathophysiology of neuronal communication in these disorders. Our study in TH deficiency contributes preliminary data that suggest abnormal D2R behavior. However the sample is short and heteregenous and further collaborative studies will be necessary to confirm these findings. The field of synaptoproteomics is currently improving and will probably increase the understanding of disease mechanisms and contribute to personalized therapeutic strategies in the future. Further studies are required to improve our knowledge of the mild and severe phenotypes of TH deficiency.

\section{Conflict of interest}

Authors state that there is no conflict of interest. 


\section{Acknowledgments}

Dr. Garcia-Cazorla is funded by the grant FIS PS09/01132. Currenty, Dr. Sofia T Duarte integrates the Portuguese Programme for Advanced Medical Education, sponsored by Calouste Gulbenkian Foundation and Portuguese Foundation for Science and Technology.

\section{References}

[1] B. Lüdecke, P.M. Knappskog, P.T. Clayton, R.A. Surtees, J.D. Clelland, S.J. Heales, et al., Recessively inherited L-dopa-responsive parkinsonism in infancy caused by a point mutation (L205P) in the tyrosine hydroxylase gene, Hum. Mol. Genet. 5 (1996) 1023-1028.

[2] G.F. Hoffmann, B. Assmann, C. Bräutigam, C. Dionisi-Vici, M. Häussler, J.B. de Klerk, et al., Tyrosine hydroxylase deficiency causes progressive encephalopathy and dopa-nonresponsive dystonia, Ann. Neurol. 54 (2003) S56-S65.

[3] Y. Furukawa, S.J. Kish, S. Fahn, Dopa-responsive dystonia due to mild tyrosine hydroxylase deficiency, Ann. Neurol. 55 (2004) 147-148.

[4] A. Schiller, R.A. Wevers, G.C. Steenbergen, N. Blau, H.H. Jung, Long-term course of L-dopa-responsive dystonia caused by tyrosine hydroxylase deficiency, Neurology 63 (2004) 1524-1526.

[5] M. Ribasés, M. Serrano, E. Fernández-Alvarez, S. Pahisa, A. Ormazabal, A. García-Cazorla, et al., A homozygous tyrosine hydroxylase gene promoter mutation in a patient with dopa-responsive encephalopathy: clinical, biochemical and genetic analysis, Mol. Genet. Metab. 92 (2007) 274-277.

[6] R. Pons, M. Serrano, A. Ormazabal, C. Toma, A. Garcia-Cazorla, E. Area, et al., Tyrosine hydroxylase deficiency in three Greek patients with a common ancestral mutation, Mov. Disord. 25 (2010) 1086-1090.

[7] M.A. Willemsen, M.M. Verbeek, E.J. Kamsteeg, J.F. de Rijk-van Andel, A. Aeby, N. Blau, et al., Tyrosine hydroxylase deficiency: a treatable disorder of brain catecholamine biosynthesis, Brain 133 (2010) 1810-1822.

[8] A. Ormazabal, M. Serrano, A. Garcia-Cazorla, J. Campistol, R. Artuch, P. Castro de Castro, et al., Deletion in the tyrosine hydroxylase gene in a patient with a mild phenotype, Mov. Disord. 26 (2011) 1558-1560.

[9] W.L. Yeung, V.C. Wong, K.Y. Chan, J. Hui, C.W. Fung, E. Yau, et al., Expanding phenotype and clinical analysis of tyrosine hydroxylase deficiency, J. Child Neurol. 26 (2011) 179-187.

[10] C.S. Chi, H.F. Lee, C.R. Tsai, Tyrosine hydroxylase deficiency in taiwanese infants, Pediatr. Neurol. 46 (2012) 77-82.
[11] T. Giovanniello, D. Claps, C. Carducci, N. Blau, F. Vigevano, I. Antonozzi, et al., A new tyrosine hydroxylase genotype associated with early-onset severe encephalopathy, J. Child Neurol. 27 (2012) 523-525.

[12] E.A. Cartier, L.A. Parra, T.B. Baust, M. Quiroz, G. Salazar, V. Faundez, et al., A biochemical and functional protein complex involving dopamine synthesis and transport into synaptic vesicles, J. Biol. Chem. 285 (2010) 1957-1966.

[13] T.J. Volz, S.J. Farnsworth, S.D. Rowley, Age-dependent differences in dopamine transporter and vesicular monoamine transporter-2 function and their implications for methamphetamine neurotoxicity, Synapse 63 (2009) 147-151.

[14] C. De Mei, M. Ramos, C. Iitaka, E. Borrelli, Getting specialized: presynaptic and postsynaptic dopamine D2 receptors, Curr. Opin. Pharmacol. 9 (2009) 53-58.

[15] S.B. Glickstein, C. Schmauss, Dopamine receptor functions: lessons from knockout mice, Pharmacol. Ther. 91 (2001) 63-83.

[16] S.T. Duarte, C. Ortez, A. Pérez, R. Artuch, A. García-Cazorla, Analysis of synaptic proteins in the cerebrospinal fluid as a new tool in the study of inborn errors of neurotransmission, J. Inherit. Metab. Dis. 34 (2011) 523-528.

[17] L.B. Møller, A. Romstad, M. Paulsen, P. Hougaard, A. Ormazabal, M. Pineda, et al., Preand postnatal diagnosis of tyrosine hydroxylase deficiency, Prenat. Diagn. 25 (2005) 671-675.

[18] K. Hyland, The lumbar puncture for diagnosis of pediatric neurotransmitter diseases, Ann. Neurol. 54 (2003) S13-S17.

[19] A. Ormazábal, A. García-Cazorla, A. Fernández, E. Fernández-Alvarez, J. Campistol, R. Artuch, HPLC with electrochemical and fluorescence detection procedures for the diagnosis of inborn errors of biogenic amines and pterins, J. Neurosci. Methods 142 (2005) 153-158.

[20] K.Y.Araki, J.R. Sims, P.G. Bhide, Dopamine receptor mRNA and protein expression in the mouse corpus striatum and cerebral cortex during pre- and postnatal development, Brain Res. 1156 (2007) 31-45.

[21] E. Herlenius, H. Lagercrantz, Development of neurotransmitter systems during critical periods, Exp. Neurol. 190 (2004) 8-21 (190).

[22] M.M. Iravani, A.C. McCreary, P. Jenner, Striatal plasticity in Parkinson's disease and L-dopa induced dyskinesia, Parkinsonism Relat. Disord. 18 (2012) 123-125.

[23] P. Calabresi, B. Picconi, A. Tozzi, M. Di Filippo, Dopamine-mediated regulation of corticostriatal synaptic plasticity, Trends Neurosci. 30 (2007) 211-219.

[24] J.A. Beeler, M.J. Frank, J. McDaid, E. Alexander, S. Turkson, M.S. Bernandez, et al., A role for dopamine-mediated learning in the pathophysiology and treatment of Parkinson's disease, Cell Rep. 2 (2012) 1747-1761. 